\title{
Stem cell applications in military medicine
}

\author{
Gregory T Christopherson' and Leon J Nesti ${ }^{1,2 *}$
}

\begin{abstract}
There are many similarities between health issues affecting military and civilian patient populations, with the exception of the relatively small but vital segment of active soldiers who experience highenergy blast injuries during combat. A rising incidence of major injuries from explosive devices in recent campaigns has further complicated treatment and recovery, highlighting the need for tissue regenerative options and intensifying interest in the possible role of stem cells for military medicine. In this review we outline the array of tissue-specific injuries typically seen in modern combat - as well as address a few complications unique to soldiers - and discuss the state of current stem cell research in addressing each area. Embryonic, induced-pluripotent and adult stem cell sources are defined, along with advantages and disadvantages unique to each cell type. More detailed stem cell sources are described in the context of each tissue of interest, including neural, cardiopulmonary, musculoskeletal and sensory tissues, with brief discussion of their potential role in regenerative medicine moving forward. Additional commentary is given to military stem cell applications aside from regenerative medicine, such as blood pharming, immunomodulation and drug screening, with an overview of stem cell banking and the unique opportunity provided by the military and civilian overlap of stem cell research.
\end{abstract}

\section{Introduction}

There is a lack of true stem cell therapies and applications [1] in both civilian and military medical populations. Some commercially available bone treatments utilize components of mesenchymal stem cells (MSCs; Cellect [2] and Trinity [3]), and a small number of applications

*Correspondence: leon.nesti@nih.gov

'The National Institutes of Health, The National Institute of Arthritis and

Musculoskeletal and Skin Diseases, Bethesda, MD 20892, USA

Full list of author information is available at the end of the article apply hematopoietic stem cells (HSCs) typically harvested from umbilical cord blood [4], but no pure Food and Drug Administration (FDA)-approved stem cell therapies are presently employed [1]. Since there is no large-scale stem cell usage, much of the excitement surrounding stem cell therapies still lies within the promise that these cells hold. This is particularly true for the military, where stem cells have the capacity to revolutionize the therapeutic approach and degree of recovery for soldiers both on and off the battlefield. This review highlights the disparity between military and civilian injuries, with a focus on how stem cells may be utilized in both a regenerative and supportive role. Since stem cell applications are still in such early stages, the majority of work presented projects forward, anticipating how stem cells may help alleviate issues specific to soldiers in modern combat.

\section{Stem cells: definitions and sources}

A stem cell is an extraordinary kind of cell that has a unique ability to renew itself indefinitely while retaining the capacity to differentiate into any cell type in the body [5]. This cellular plasticity makes them a promising cell source for replacing and/or regenerating destroyed tissue. There are predominantly three classes of stem cells: adult stem cells (ASCs), embryonic stem cells (ESCs) and induced pluripotent stem cells (iPSCs) [6], each with its own advantages and disadvantages (Figure 1). The therapeutic merits of each cell type are widely debated among experts; ASCs are the point of focus here, but likely all stem cell sources will be of future benefit.

\section{Military versus civilian perspective}

In peacetime there are few, if any, differences between military and civilian medical populations; however, wartime combat injuries introduce a novel set of trauma patients into the military medical system, stressing the current treatment paradigms for acute trauma. These injuries - particularly in the modern era of insurgency and improvised explosive devices (IEDs) [7] - are of unusually high energy and they occur in a relatively young, healthy patient population [8]. Although civilian blast injuries are more infrequent, they are occurring at an increasing rate - particularly worldwide, in cases of domestic terrorism - allowing for selective overlap of 


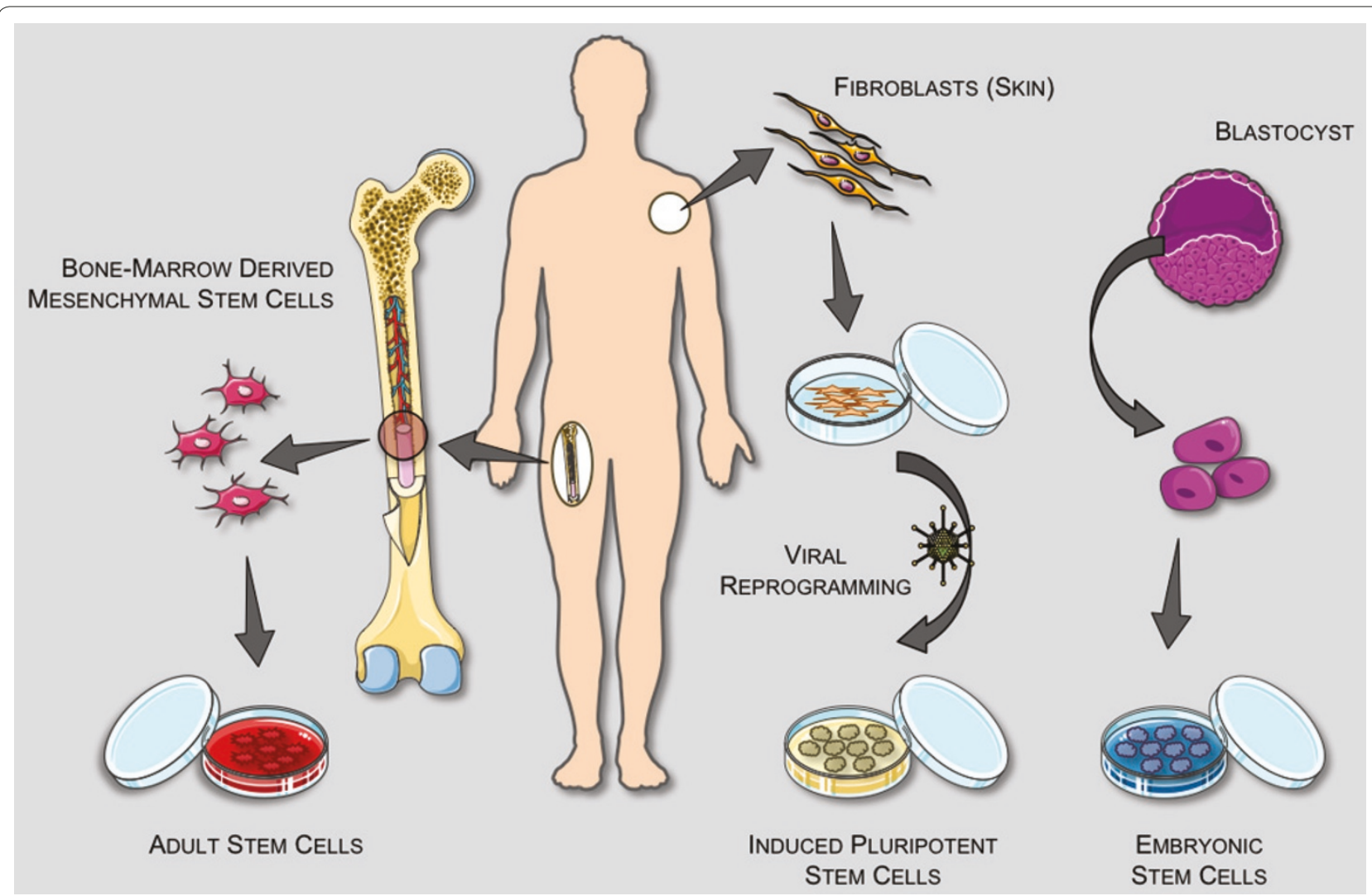

Figure 1. Stem cell sources and definitions. A stem cell is a cell capable of proliferating for long periods and differentiating into specialized cells that make up the tissues and organs of the body. A single pluripotent stem cell can give rise to cells that develop all three germ layers (mesoderm, endoderm, ectoderm) that constitute the body. There are three general classifications of stem cells: adult stem cells (ASCs), embryonic stem cells (ESCS), and induced pluripotent stem cells (iPSCs). An ASC is an undifferentiated (unspecialized) cell that occurs in a differentiated (specialized) tissue, renews itself, and becomes specialized to yield all of the cell types of the tissue from which it originated. ASCs usually divide to generate progenitor or precursor cells, which then differentiate or develop into 'mature' cell types that have characteristic shapes and specialized functions They have a more limited differentiation profile (termed 'multipotent') than pluripotent ESCs/iPSCs, but are non-tumorigenic, and can be isolated and/or mobilized from many tissue sources, likely making them the most readily adapted cell source for regenerative medicine. The most well researched ASCs are mesenchymal and hematopoietic stem cells, originally isolated from bone marrow. An ESC is derived from a group of cells called the inner cell mass, which is part of the early (4- to 5-day) embryo called the blastocyst. Once removed from the blastocyst, the cells of the inner cell mass can be cultured into ESCS. ESCs have nearly unlimited proliferation and differentiation potential, but there are intrinsic tumor and ethical concerns, and differentiation pathways are poorly understood/controlled currently. An iPSC is a stem cell that has been created from an adult cell - such as skin or blood - through the introduction of genes that reprogram it into a cell with the characteristics of an ESC. iPSCs have the advantage of not having to be derived from human embryos, a major ethical consideration. Another critical advantage of iPSC technology is that, in theory, it allows for the creation of cell lines that are genetically customized to a patient, bypassing issues of immune rejection. Retroviral induction is currently required to reprogram adult cells, which is problematic. It also remains to be seen whether reprogrammed skin cells differ in significant ways from ESCs, but in early studies they appear to exhibit the same key features: the ability to differentiate to any of the 220 types of cells in the human body, and the ability to reproduce indefinitely in culture. Readers interested in more general information about stem cells are referred to the NIH Stem Cell Information web site [109]. Servier Medical Art (Servier, Suresnes, France) was used in assembling Figure 1.

both research and treatment models typically focused on military casualties $[9,10]$. The high degree of tissue loss and destruction associated with these injuries is one of the defining characteristics of modern combat and presents the biggest clinical treatment dilemma. The customary priorities of skeletal stabilization and tissue repair have been replaced with provisional skeletal stabilization and tissue replacement or regeneration. Cell-based treatment options are most desirable, with an end goal of restoring full or partial tissue structure and function. Unfortunately, there are currently no effective options available, primarily due to the limited healing capacity of native (adult) cells.

Because of this, stem cells possess high value as a tissue regenerative source for combat injury applications, particularly ASCs, as age concerns of the native cells are mitigated [11] in a young, healthy patient population. Some of the supportive (trophic) properties of stem cells are also highly desirable, allowing for proper wound healing and recovery without requiring en masse 
replacement of severely injured tissue, making stem cells increasingly valuable for both in vitro and in vivo applications in regenerative medicine [12]. Stem cells also play a powerful role aside from tissue regeneration, holding promise in alternative applications: emergency/front-line blood supplies; drug/vaccine screening for biowarfare; and immunomodulation to alleviate rejection of transplanted tissues.

We will briefly discuss stem cell potential in both a regenerative and auxiliary capacity here, highlighting the most promising current directions. Emphasis is given to the most-current review literature for reader reference.

\section{Applications in trauma and regenerative medicine}

There are promising in vitro and in vivo approaches for utilizing stem cells in regenerative medicine, defined by the National Institutes of Health as the process of creating living, functional tissues to repair or replace tissue or organ function lost due to age, disease, damage, or congenital defects' [5]. Nearly all tissues are of military interest, due to the diverse nature of injuries associated with war trauma (Figure 2). The increase in explosive attacks in current conflicts often results in massive wounds involving multiple organs [13], making all realms of tissue reconstitution a primary goal of military stem cell applications. To properly engineer complex tissues, stem cells will likely need to be augmented by biomaterials, which are not discussed in detail here (the authors recommend the following reviews: opinion on importance of synthetic biomaterials in tissue engineering [14]; current commercial biomaterials and future perspectives [15]; nerve guides [16]). It is rare to have localized, singular tissue damage from combat injuries, and there is always a mix of integrated cell types; but for simplicity of presentation to the reader, individual cell types are discussed here.

\section{Sensory tissues}

The use of polycarbonate eye armor has acted to reduce the number of eye injuries from historic rates, but the current reliance on high explosive fragmentary munitions has actually led to a higher rate of severe ocular injuries with unique patterns [17]. Photoreceptors and retinal neurons do not spontaneously regenerate, making vision loss a permanent proposition in most instances. In rare cases eye transplants are viable, but it is thought that relatively immature (non-cadaver) cell sources have the best chance of host-integration [18]. Recently, retinal cells have been produced from embryonic sources [19] and ASC sources are showing progress towards creating an ocular stem cell [20], creating optimism that substantial strides can be made in vision restoration.

Auditory loss is one of the more common sensory losses from blast trauma. Supersonic blasts from military

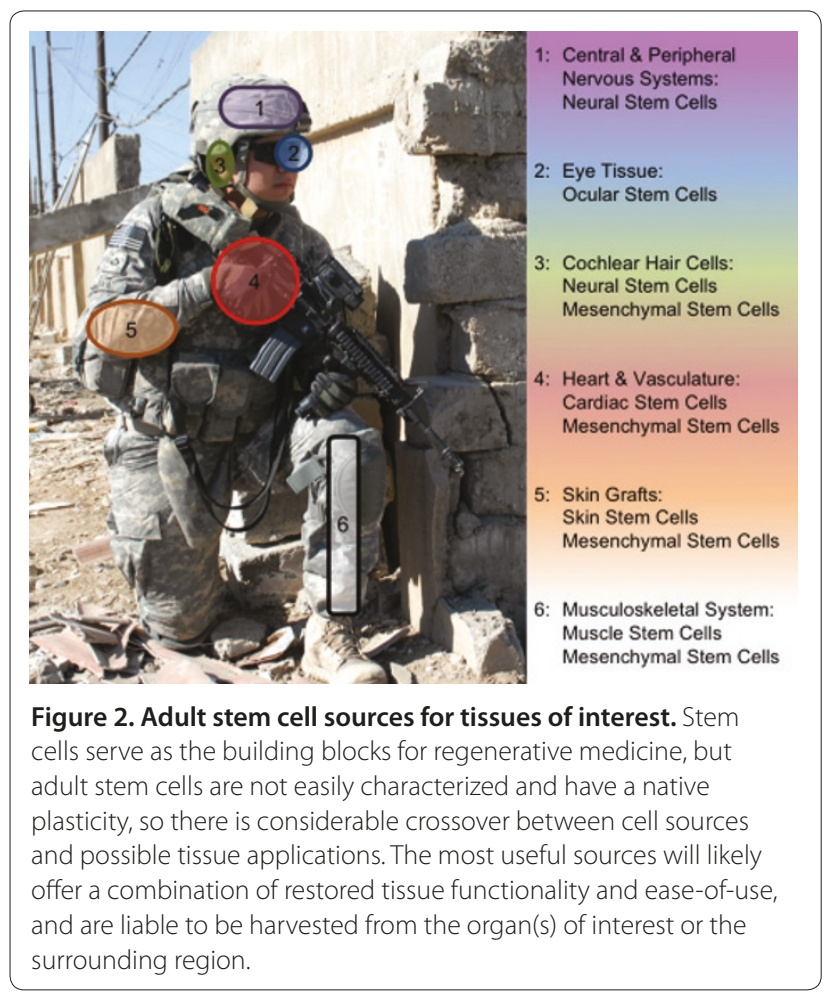

explosives and armament lead to biochemical and mechanical injury to the inner and outer ear, usually in the form of sensory hair loss. Damage to even a marginal portion of the non-regenerative cochlear hair cells can result in terminal hearing loss and issues of vertigo [21]. Stem cell transplantation of a variety of sources has only been partially successful in animal models [22]. Neural stem cells have shown similar characteristics to the inner ear hair cells and the ability to reestablish some auditory contacts, generating a possible tool for studying more suitable future replacements [23], either by differentiation of MSCs, or identification of stem cells that potentially reside in the cochlea and/or inner ear [24]. In the event that hair cells can be produced, issues of nervous reintegration will still need to be overcome to have any restoration of hearing and balance [21].

\section{Nervous tissue}

Injuries to the central and peripheral nervous systems are dually damaging, resulting in impairment of proper physical and psychological function. The focus in this section is applying stem cells for structural regeneration of damaged neural tissues; psychological factors are discussed later. In regards to physical damage, there is unfortunately no readily available statistic for nerve injuries resulting from recent military campaigns, but peripheral nerve injuries occurred in approximately $25 \%$ of extremity war wounds during the Vietnam conflict 
[25]. With an increasing number of casualties resulting from explosive mechanisms (77 to $84 \%$ during Iraq and Afghanistan) [26], that number is likely much higher in modern combat, particularly the component of concussive blast damage inflicted on the central nervous system, which is difficult to ascertain. Some experts posit that nearly any high energy injury will have resulting nervous tissue damage, making this a large area of military concern.

Generally speaking, there are three types of nervous tissue injuries: brain, spinal cord and peripheral nerves. At this time, damage to brain tissue is irreversible, with very limited understanding of how to structurally repair such a complex organ; any realistic discussion of reconstructing brain tissue is far reaching and beyond the scope of this review. Spinal cord damage is physically devastating, involving the loss of sensory and motor function below the level of injury, with further secondary damage caused by inflammation and other local mechanisms [27]. This environment destroys local healthy cells - primarily neurons and the oligodendrocytes that myelinate them - and prevents axonal regeneration. Peripheral nerves are the most commonly injured in combat, resulting from high-velocity gunshot wounds and explosive fragments [28]. In some cases peripheral nerves are lacerated and are amenable to direct repair, but most involve a zone of injury that requires complex strategies to facilitate end organ re-innervation. Fracture stabilization, repair of vascular injury and tissue debridement often take precedence over nerve repair, and may lead to delays in addressing damaged nerves, further complicating peripheral nerve treatment [28]. In any type of nervous tissue injury, there is typically neuropathic pain, experienced as sharp, burning or stabbing sensations, which combined with limited motor recovery and subsequently limited functional recovery makes even partial restoration a clear goal [13].

As with the majority of available literature regarding stem cells, little direct work has been done with stem cells specifically for military applications, but there is a direct correlation that can be drawn from research done for diseases affecting the general population. In this case, there is a large collection of stem cell-based neural research [29] that is targeted at providing novel strategies to treat the debilitating effects of neurodegenerative diseases. So far these strategies have been met with modest and temporary gains as treatment options in both the central [30] and peripheral nervous systems [31]. Spinal cord and peripheral nerve injuries may benefit directly from multiple strategies applied towards neurogenesis and remyelination, primarily with neural stem cells and/or oligoprogenitors [30-32]. As alluded to earlier, artificial nerve guides may greatly improve recovery, and are an area of eminent interest [16]. Like many stem cell discussions, there is split opinion whether adult, embryonic or induced-pluripotent stem cells hold the most potential going forward [33]. Despite so much work being done in the central and peripheral nervous system research arenas, no clinical applications are yet available, particularly for cases of trauma. The more substantial impact has been made in mechanistic understanding of cells, injuries and their microenvironment, allowing for better future strategies [34].

\section{Musculoskeletal tissues}

Nearly all modern combat injuries have some degree of musculoskeletal damage (bone, fat, muscle, connective tissues, and so on), making it a prioritized area of military research [35]. Better body armor, trained combat medics, point of injury care, rapid evacuation and forwardoperating surgical assets have all greatly increased soldier survival, but the percentage of injuries that are orthopedic in nature has remained remarkably steady at around $65 \%$ of total casualties [36]. Musculoskeletal injuries greatly limit patient mobility, and commonly have a high rate of pain, due to penetrating fragment injuries and secondary strains/sprains caused by the severe force associated with blast-type weapons [13]. There is also a high incidence of ectopic bone formation (heterotopic ossification), typically associated with blast injuries [37], which can cause considerable pain, poor prosthesis fitting, limit joint mobility and require secondary surgeries for removal. The causes of heterotopic ossification are still unknown and are under investigation, but are believed to result from local stem cell confusion [38].

New stem/progenitor cell sources within the musculoskeletal tissue are constantly being discovered (wholly labeled here as MSCs), with their availability and differentiation profile making them an extensively examined stem cell source, and a most promising cell group for future therapies [39]. MSCs were first isolated from bone marrow, and gained a widespread connotation as being mesenchymal, but recent isolation of cells with similar characteristics from various other tissues has led to more defined descriptors - bone marrow stromal cells, adiposederived stem cells [40], and mesenchymal progenitor cells [41] or muscle-derived stem cells [42] - all of which have been shown to be capable of differentiating into the principle cell types within the musculoskeletal system (osteoblasts, adipocytes, chondrocytes) as well as cardiac and neural lineages. Bone marrow stromal cells are the most well-characterized of these MSC stem/progenitor sources (and it has been argued that other forms are less primitive MSCs), but multiple sources are currently in a wide range of clinical trials dealing with cardiac, osteogenic and neurological diseases [43], with potential applications in urological diseases [44]. Expert opinions supporting the most promising cell type are widely varied [45-49], with the area of regeneration possibly playing a 
key role in cell choice, as well as ease of isolation. There is a prevailing thought that for any structural support tissues, a mixture of cells and scaffolding is required [50], in which biomaterials selection will be critical - and likely complicated [51].

\section{Circulatory-pulmonary tissues}

Pulmonary injuries are one of the most obvious examples of how war-trauma and associated treatments customarily differ from their civilian equivalents. Civilian pulmonary trauma is uncommon, so except in select incidences [52] most medical research is based around the model of lung cancer. There are a variety of lung injuries that affect soldiers in combat, with many sequelae. Most blastrelated injuries include penetrating trauma (for example, shrapnel - although often mitigated by body armor), but an entire series of additional injuries are inflicted by blast overpressure (known as blast lung [53]), ranging from arterial air emboli to pulmonary hemorrhage to lung contusions [10,54]. Injuries are extensive (up to $70 \%$ of critically injured soldiers have some level of pulmonary injury) and diagnosis can be complicated by temporal variability in clinical presentation [54].

Pulmonary stem cells have been extensively studied in the civilian population with respect to their involvement in lung cancer [55]. The consensus view is that locationspecific stem cell zones exist in the lung in lieu of a single multipotential stem cell typical of other tissues [55]. The mechanistic role these cells play in cancer is under close examination, but there are few studies testing their regenerative capabilities or the role that they may play in post-traumatic injury, such as war-time trauma. Therapies directed towards pulmonary fibrosis or acute lung injuries utilizing MSCs or ESCs will likely have the most immediate benefit [56-58]. Emerging technologies are allowing for isolation and culture of certain lung progenitor cells [59], which may prove to be beneficial for combat pulmonary injuries in the distant future.

Cardiovascular trauma encompasses injury to both the heart and systemic vasculature. The high incidence of injuries to extremities makes peripheral vascular damage more common, but both heart and vessel wounds are suitable areas of stem cell application. Vessel damage from gunshot and blast shrapnel wounds is frequently complicated by skeletal fracture and soft tissue damage, and common emergency treatment methods - such as application of tourniquets - often result in iatrogenic injury, aggravating ischemia, increasing the chance of peripheral nerve injury and furthering tissue necrosis [60].

In massive soft tissue injuries there is a wide zone of injury involving veins, arteries and their collateral channels, making re-anastomosis particularly difficult. Soft tissue coverage (muscle flaps) and/or microvascular repair may be required, increasing surgical complexity. While not a direct case of vasculature regrowth, soft tissues that can be engineered from stem cells would be of great benefit in supporting vasculature treatment and repair.

The idea of using stem cells to reconstruct blood vessels appears to be a realistic near-term endeavor, as they can be readily differentiated into the endothelial and smooth muscle cells comprising native vasculature [61]. MSCs [62] and adipose-derived stem cells [63] both appear to have replacement potential as well as trophic stabilization for angiogenesis, and vascular progenitor cells derived from ESCs have formed microvessels with a degree of functional integration in mouse models [64]. Blood vessel engineering may be a particularly suitable area for biomaterials $[61,65]$.

Compared to vasculature, advances made in stem cell biology for cardiac repair are less applicable for war trauma since most therapy centers on cardiovascular disease instead of functional replacement. There is reason for optimism, however, as a wide variety of cell types have shown potential for regeneration of cardiac tissues, including MSCs, HSCs, cardiac stem cells and ESC/iPSC derivatives [66,67]. Additionally, there has been a variety of benefits in preliminary clinical trials (improved ejection fraction and myocardial perfusion) for multiple cell types of intra-cardiac and extra-cardiac origin [67], seeming to indicate that at least low levels of cardiac integration may be more readily achieved than for some of the other more complex tissues. Much of the favorable results may be due in large part to protective effects of transplanted stem cells instead of newly generated cardiac tissue [66].

\section{Other tissues}

Skin is destroyed in nearly every combat injury, with deep skin injuries generating large amounts of scar tissue. Whether due to penetrating or chemical injury, skin coverage is essential for proper wound healing, particularly in large burn injuries, where infection and dehydration are a constant concern. Fortunately, skin has a large reservoir of various stem/progenitor cells inclined to produce new epidermis [68], and is rather resilient and undergoes continuous regeneration. Ideally, skin would be similar to blood vessels, in that stem cells could be used to engineer tissue in vitro for subsequent surgical grafting, especially in major wounds where there are a lack of allograft sites available. Having a 'young' tissue (particularly if autologous stem cells can be employed) increases the odds of healthy integration with native organs, and bypasses rejection concerns associated with cadaver grafts. Current clinical results utilizing skin stem cells are unsatisfactory - usually due to poor long-term functionality - seeming to underscore the importance of combining skin stem cells with other stem cell sources to 
generate the complex tissue [69]. Despite no current clinical uses, skin stem cells remain a promising source for understanding the mechanisms of skin regeneration [70], which may help to accelerate recovery, and an active biomaterials presence [71] is helping bridge the gap until true deep-skin grafts are available in the future.

Closely associated with skin replacement is the issue of scarless healing. Although often thought of as a cosmetic improvement - which is of obvious importance to mental health and everyday recovery - scarless healing has much deeper implications. Scarification of tendons, corneal scarring, and fibrosis around medical implants/grafts are all functional concerns for both the surgeon and the patient [72]. Scar tissue is functionally, mechanically and structurally inferior to native tissue, and is often associated with pain [72]. Additionally, scar tissue formation has been implicated in certain disease pathogenesis, such as heterotopic ossification [73]. A great deal of effort has been put towards unraveling the mechanisms of scarless healing, generally associated with healing in utero [72]. Despite extensive investigation, the specifics of fetal wound healing remain a mystery, although it is believed fetal healing may rely on a different cellular signaling cascade than adults, possibly involving HSCs and epidermal stem cells $[74,75]$. It is not surprising that stem cells may be implicated; although at this point there is no understanding of how they may help to alleviate scar formation, they remain an intense area of interest moving forward.

Renal injuries are typically fatal in combat [76]. Fortunately, in the case of acute kidney injury, soldier complications are often similar to those of civilian and nonwartime patients who require transplantation, so many of the advancements and treatment protocols developed during peacetime carry over to soldier care. Renal progenitor cells have been isolated from the kidney, and MSCs appear to be a likely candidate for kidney reconstitution, although not in the near future [77].

\section{Trophic/modulating properties}

Much of the original excitement surrounding stem cells centered on their potential to directly restore and replace dysfunctional tissue; however, this may be a simplistic and limited view of their true potential. Many of these cells offer a protective and/or directive potential at sources of injury, initially seen in MSCs [12,78], but now characterized across a series of cell types [78,79]. These trophic characteristics have been shown to help direct healing by secreting a variety of bioactive molecules and preparing a functionally desirable extracellular matrix - a prerequisite to proper cellular growth and integration. The carefully orchestrated production of growth factors and cytokines helps effect a therapeutic outcome, likely by inhibiting cell apoptosis and scar formation while stimulating angiogenesis and cell mitosis [78]. These supportive and directive characteristics of stem cells are not completely understood and are far from being fully characterized, but it is likely that as their supportive role in tissue genesis and repair unfolds it may prove to be their most valuable quality. Any method for heightening the healing response is of great interest for military medicine; this guiding capability of stem cells adds a new wrinkle to their application in tissue engineering and regenerative medicine, whose potential is just now being unraveled.

\section{Auxiliary applications}

To this point, our commentary has focused almost exclusively on the application of stem cells in regenerative medicine, and this is the most promising aspect of stem cells for military medical purposes; however, a series of other applications harness their unique properties in alternative ways. These are briefly described, to give a more inclusive view of stem cell capabilities.

\section{Blood pharming}

The military has historically sought after a synthetic or readily obtainable in vitro source of red blood cells and platelets. Blood shortages are common, especially in far forward positions during mass casualty events, and there are safety and cost concerns associated with disease screening and storage. The Defense Advanced Research Projects Agency (DARPA) is actively funding projects to develop 'novel technologies to enable in vitro production of red blood cells that are untainted, readily available, and free of storage lesions' [80]. It has long been recognized that stem cells (HSCs in particular) could potentially remove the burden associated with blood supplies both at home and abroad, but progress has been slow, despite the high demand. Bottlenecks currently exist in differentiating pure populations of red blood cells from a stem cell source, as well as creating a bioreactor capable of producing the large volumes required for viable applications [81].

\section{Immunobiology}

The use of HSCs and/or MSCs in immunosuppression and immunomodulation is an area of active and exciting research. Inflammation and the resulting inflammatory cascade resulting from acute injury or infection is the necessary 'first step' in mounting an immune response or initiating tissue repair, but often times the body's overly robust response to insult has significant detrimental effects. Stem cells may offer a new strategy to modulate, or control, this systemic response.

Infection can pose a significant problem to soldiers who sustain combat wounds. Environmental contamination, the reduced catecholic state of soldiers in extended 
conflict and the uneven or uncertain level of medical care from time of injury may all contribute to the complications that arise from an infected war wound, but the body's ability to respond to and control the infection while maintaining the ability to repair the damaged tissue will ultimately determine the overall outcome for the soldier. In certain instances an infection may overwhelm the native defense mechanisms, leading to overwhelming sepsis and death, while in other instances the patient may be able to mount an appropriate response and heal uneventfully. More often than not, the ultimate result is somewhere between those two extremes. Long-term sequelae resulting from infection are common and wide in scope. For example, it has been reported that up to $15 \%$ of combat-related extremity injuries develop osteomyelitis [36], a chronic infection of the bone. This condition has a protracted course, often requiring multiple surgical procedures over many years and can ultimately result in amputation or death. Stem cells may prove useful in augmenting the body's initial response to infection as well as improving the ability to treat long-term sequelae such as osteomyelitis [82-86].

Stem cell-based immunomodulation of tissue allotransplantation is also starting to show promise. Stem cells are valuable in immunobiology, as a means of both examining and potentially controlling immune responses [87]. Allogenic HSC transplantation has become a common procedure for treating immunodeficiency disorder by redirecting the immune system, but often with severe reactions [88]. MSCs show large potential as immunomodulators by skewing the immune response towards more tolerant phenotypes, reducing the generation of dendritic cells and suppressing effector $\mathrm{T}$ cells [87]. Although the mechanisms are still unclear, immunosuppression pathways are diligently being unraveled [89], with increased benefits being seen when MSCs and HSCs are applied in conjunction [90]. These results make immunosuppressive drug-free allotransplantation a real possibility, a concept that may have enormous impact for the field of composite tissue allotransplantation (that is, hand transplantation, face transplantation, and so on). Currently, composite tissue allotransplantation treatment options for non-fatal conditions have not received widespread acceptance because of the requirement for lifelong immunosuppressive treatment, negatively impacting many disfigured and dysfunctional soldiers as they reintegrate into society.

\section{Role of neural stem cells in cognitive behavior}

Traumatic brain injury has been one of the hallmark injuries associated with the wars in Iraq and Afghanistan [91]. Because there is a lack of concrete evidence, opinions are divided on the role and possible mechanisms of blast waves in causing neurotrauma, and the resultant effects on the central and peripheral nervous systems [91]. What is not debated is the effect traumatic brain injury can have psychologically, resulting in depression, substance abuse, personality disorder and sharing many of the same clinical features as post-traumatic stress disorder $[92,93]$. The current role of neural stem cells in dictating cognitive behavior is unclear, but they are a key component of neurogenesis and have been linked to post-traumatic stress disorder [94], stress-triggered depression [95] and other common aspects of mental health [96]. It is of utmost importance that soldiers be able to seamlessly incorporate back into society and retain a quality of life both physically and psychologically after serving. A better understanding of stem cell impact on thinking and reasoning - however complex - has obvious implications for how to best train and treat soldiers experiencing stressful situations during and following combat.

\section{Drug/vaccine screening, biosensors}

The increasing use of chemicals in blast weapons [8] underscores the importance of understanding chemical effects on tissues. In modern warfare, radiation and bioweapons are also major concerns. The primary impact that stem cells may eventually have in diminishing these concerns revolves around their regenerative effects, as previously described. There is also a role for stem cells in screening and preventative measures. Computer modeling has shown the effect high radiation may have on HSC populations and leukemia [97], allowing us to infer what impact it may have on tissue regeneration. In more direct experimentation, mustard gas damage to eyes [98] and skin [99] has been evaluated, allowing for initial estimations to be made for how stem cells may speed the healing process; similar corollaries have been made for brain and bone marrow damage from soman exposure [100]. With stem cells being so key to many ongoing regenerative processes in the body, it will be important to determine how they are affected by various weapons of a non-physical nature, to better understand short- and long-term consequences of soldier health following exposure. This area of research has been scantly covered.

Stem cells can also function as detection and screening agents. Currently, B cells have been employed as cell-based biosensors [101] for certain pathogens, and attempts are being made to alter them for use in explosive and chemical detection; due to their plasticity, there is hope that stem cells may be tailored to make biosensors with greater sensitivity or specificity [102]. Additional work is being done to utilize stem cells in early stage drug and vaccine screening [103]; currently in nascent stages, there are a series of obstacles to overcome, but - like most stem cells applications - it has the potential to revolutionize the drug discovery process. 


\section{Stem cell banking}

One issue that has not been addressed is the source of stem cells that can be tapped for regenerative and auxiliary applications. This is partly because each stem cell type has its own distinct advantages and disadvantages, with the best candidate for each procedure likely winning out in time. General early consensus is that autologous sources (ASCs or iPSCs) may hold the greatest potential, due to a lack of immune rejection, but allogeneic sources have been successfully used previously, and ESC-derived tissues may very well not elicit an immune response, either naturally or by biological programming. In the case of ASCs and/or iPSCs, one proposed idea is to create a biobank of tissues for active military personnel, whereby prior to deployment soldiers will provide tissue biopsies for long-term storage and eventual self-treatment in the event of injury. Biobanks are commonly utilized for infant cord blood [104], and act as tissue and/or cell repositories, holding an immediate and safe reservoir of cells that can be therapeutically applied.

While certainly a promising concept, biobanks have serious limitations. There are a myriad of legal and technical issues, many of which are similar to commercial stem cell banking initiatives [105]. Additionally, some cells cannot be readily isolated (neural stem cells), and others require invasive procedures (bone marrow and adipose aspirates). It is also likely cost prohibitive to stem cell bank the entire active military for the small fraction that will experience a traumatic injury, as well as arrange for off-site cell expansion and delivery. Moreover, in the event of traumatic injury some previously nonexistent stem cells are 'activated' and found in large concentrations in the wounded tissue [106]; when taken in consideration with advances that have been made in isolating stem cells during surgical operations, there is debate as to the effectiveness of using frozen tissue versus fresh isolates. Despite these limitations, the intrinsic value of readily available, autologous, non-immunocompromised tissue makes biobanks a significant concept worth careful evaluation. Regardless of what is determined to be the best direction, decisions will have to be made concerning how best to harvest stem cells for eventual military application, likely based on the most promising emerging research.

\section{Conclusion}

The vast majority of stem cell excitement has yet to be realized clinically, but the potential impact on regenerative medicine and auxiliary applications, such as blood pharming and immunomodulation, make stem cells an area of great interest to the military. Historically, the most significant advances in military medical research have arisen from investigative efforts focused on problems facing a deployed military force, and many of these advances have led to direct applications in civilian medical care $[107,108]$. Medical problems facing the deployed forces in the recent conflicts in Iraq and Afghanistan have spurred a new wave of military medical research, much of which will benefit from stem cell therapies. Only time will tell whether or not researchers are able to capitalize on advancements targeted for diseases in the general population and apply those for purposes beneficial to those in uniform.

\section{Abbreviations}

ASC, adult stem cell; ESC, embryonic stem cell; HSC, hematopoietic stem cell; iPSC, induced pluripotent stem cell; MSC, mesenchymal stem cell.

\section{Competing interests}

The authors declare that they have no competing interests.

\section{Acknowledgements}

The authors thank LCDR Jared Vogler, MD, and Wesley Jackson, PhD, for their helpful discussion and manuscript review. Work in the Nesti lab is supported by the Military Amputee Research Program (PO5-A011) and the NIH/NIAMS intramural program.

\section{Author details}

'The National Institutes of Health, The National Institute of Arthritis and Musculoskeletal and Skin Diseases, Bethesda, MD 20892, USA. ${ }^{2}$ Hand and Upper Extremity Reconstructive Surgery Service, Department of Orthopaedic Surgery, McDonald Army Medical Health Center, Ft Eustis, VA 23604, USA.

Published: 19 October 2011

References

1. Smith S, Neaves W, Teitelbaum S: Adult stem cell treatments for diseases? Science 2006, 313:439.

2. Lee K, Goodman SB: Cell therapy for secondary osteonecrosis of the femoral condyles using the Cellect DBM System: a preliminary report. J Arthroplasty 2009, 24:43-48.

3. Rush SM, Hamilton GA, Ackerson LM: Mesenchymal stem cell allograft in revision foot and ankle surgery: a clinical and radiographic analysis. J Foot Ankle Surg 2009, 48:163-169.

4. Reimann V, Creutzig U, Kögler G: Stem cells derived from cord blood in transplantation and regenerative medicine. Dtsch Arztebl Int 2009, 106:831-836.

5. Department of Health and Human Services: Regenerative Medicine. $\mathrm{NIH}$; 2006 [http://stemcells.nih.gov/staticresources/info/scireport/pdfs/ regenerative_medicine_2006.pdf]

6. Takahashi K, Yamanaka S: Induction of pluripotent stem cells from mouse embryonic and adult fibroblast cultures by defined factors. Cell 2006, 126:663-676.

7. Ritenour AE, Blackbourne LH, Kelly JF, McLaughlin DF, Pearse LA, Holcomb JB, Wade CE: Incidence of primary blast injury in US military overseas contingency operations: a retrospective study. Ann Surg 2010, 251:1140-1144.

8. Champion HR, Holcomb JB, Young LA: Injuries from explosions: physics, biophysics, pathology, and required research focus. J Trauma 2009, 66:1468-1477; discussion 1477.

9. Irwin RJ, Lerner MR, Bealer JF, Lightfoot SA, Brackett DJ, Tuggle DW: Global primary blast injury: a rat model. J Okla State Med Assoc 1998, 91:387-392

10. Kirkman E, Watts S, Cooper G: Blast injury research models. Philos Trans R Soc Lond B Biol Sci 2011, 366:144-159.

11. Rando TA: Stem cells, ageing and the quest for immortality. Nature 2006, 441:1080-1086.

12. Caplan Al: Adult mesenchymal stem cells for tissue engineering versus regenerative medicine. J Cell Physiol 2007, 213:341-347.

13. Clark ME, Scholten JD, Walker RL, Gironda RJ: Assessment and treatment of pain associated with combat-related polytrauma. Pain Med 2009, 10:456-469. 
14. Lutolf MP, Hubbell JA: Synthetic biomaterials as instructive extracellular microenvironments for morphogenesis in tissue engineering. Nat Biotechnol 2005, 23:47-55.

15. Place ES, Evans ND, Stevens MM: Complexity in biomaterials for tissue engineering. Nat Mater 2009, 8:457-470.

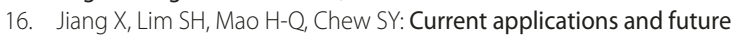
perspectives of artificial nerve conduits. Exp Neurol 2010, 223:86-101.

17. Weichel ED, Colyer MH: Combat ocular trauma and systemic injury. Curr Opin Ophthalmol 2008, 19:519-525.

18. Lamba DA, Karl MO, Reh TA: Strategies for retinal repair: cell replacement and regeneration. Prog Brain Res 2009, 175:23-31.

19. Osakada F, Ikeda H, Sasai Y, Takahashi M: Stepwise differentiation of pluripotent stem cells into retinal cells. Nat Protoc 2009, 4:811-824.

20. Jeganathan VSE, Palanisamy M: Treatment viability of stem cells in ophthalmology. Curr Opin Ophthalmol 2010, 21:213-217.

21. Edge AS, Chen ZY: Hair cell regeneration. Curr Opin Neurobio/ 2008 , 18:377-382.

22. Vlastarakos PV, Nikolopoulos TP, Tavoulari E, Papacharalambous G, Tzagaroulakis A, Dazert S: Sensory cell regeneration and stem cells: what we have already achieved in the management of deafness. Otol Neurotol 2008, 29:758-768.

23. Collado MS, Holt JR: Can neurosphere production help restore inner ear transduction? Proc Natl Acad Sci U S A 2009, 106:8-9.

24. Kesser BW, Lalwani AK: Gene therapy and stem cell transplantation: strategies for hearing restoration. Adv Otorhinolaryngol 2009, 66:64-86.

25. Stanec S, Tonkovic I, Stanec Z, Tonkovic D, Dzepina I: Treatment of upper limb nerve war injuries associated with vascular trauma. Injury 1997, 28:463-468

26. Owens BD, Kragh JF Jr, Macaitis J, Svoboda SJ, Wenke JC: Characterization of extremity wounds in Operation Iraqi Freedom and Operation Enduring Freedom. J Orthop Trauma 2007, 21:254-257.

27. Wu B, Ren X: Promoting axonal myelination for improving neurological recovery in spinal cord injury. J Neurotrauma 2009, 26:1847-1856.

28. Ecklund JM, Ling GS: From the battlefront: peripheral nerve surgery in modern day warfare. Neurosurg Clin N Am 2009, 20:107-110, vii.

29. Lindvall O, Kokaia Z: Stem cells in human neurodegenerative disorders time for clinical translation? J Clin Invest 2010, 120:29-40.

30. Franklin RJM, Ffrench-Constant C: Remyelination in the CNS: from biology to therapy. Nat Rev Neurosci 2008, 9:839-855.

31. Walsh S, Midha R: Use of stem cells to augment nerve injury repair. Neurosurgery 2009, 65:A80-86.

32. Nandoe Tewarie RS, Hurtado A, Bartels RH, Grotenhuis A, Oudega M: Stem cell-based therapies for spinal cord injury. J Spinal Cord Med 2009, 32:105-114.

33. Salewski RP, Eftekharpour E, Fehlings MG: Are induced pluripotent stem cells the future of cell-based regenerative therapies for spinal cord injury? J Cell Physiol 2010, 222:515-521

34. Ronaghi M, Erceg S, Moreno-Manzano V, Stojkovic M: Challenges of stem cell therapy for spinal cord injury: human embryonic stem cells, endogenous neural stem cells, or induced pluripotent stem cells? Stem Cells 2010, 28:93-99.

35. Belmont PJ, Schoenfeld AJ, Goodman G: Epidemiology of combat wounds in operation iraqi freedom and operation enduring freedom: orthopaedic burden of disease. J Surg Orthop Adv 2010, 19:2-7.

36. Murray CK, Hsu JR, Solomkin JS, Keeling JJ, Andersen RC, Ficke JR, Calhoun JH: Prevention and management of infections associated with combatrelated extremity injuries. J Trauma 2008, 64:S239-251.

37. Cipriano CA, Pill SG, Keenan MA: Heterotopic ossification following traumatic brain injury and spinal cord injury. J Am Acad Orthop Surg 2009, 17:689-697.

38. Jackson WM, Aragon AB, Bulken-Hoover JD, Nesti LJ, Tuan RS: Putative heterotopic ossification progenitor cells derived from traumatized muscle. J Orthop Res 2009, 27:1645-1651.

39. Baksh D, Yao R, Tuan RS: Comparison of proliferative and multilineage differentiation potential of human mesenchymal stem cells derived from umbilical cord and bone marrow. Stem Cells 2007, 25:1384-1392.

40. Bunnell BA, Flaat M, Gagliardi C, Patel B, Ripoll C: Adipose-derived stem cells: isolation, expansion and differentiation. Methods 2008, 45:115-120.

41. Nesti LJ, Jackson WM, Shanti RM, Koehler SM, Aragon AB, Bailey JR, Sracic MK, Freedman BA, Giuliani JR, Tuan RS: Differentiation potential of multipotent progenitor cells derived from war-traumatized muscle tissue. J Bone Joint
Surg 2008, 90:2390-2398

42. Qu-Petersen Z, Deasy B, Jankowski R, lkezawa M, Cummins J, Pruchnic R Mytinger J, Cao B, Gates C, Wernig A, Huard J: Identification of a novel population of muscle stem cells in mice: potential for muscle regeneration. J Cell Biol 2002, 157:851-864.

43. Giordano A, Galderisi U, Marino IR: From the laboratory bench to the patient's bedside: an update on clinical trials with mesenchymal stem cells. J Cell Physio/ 2007, 211:27-35.

44. Montzka K, Heidenreich A: Application of mesenchymal stromal cells in urological diseases. BJU Int 2010, 105:309-312.

45. Patterson TE, Kumagai K, Griffith L, Muschler GF: Cellular strategies for enhancement of fracture repair. J Bone Joint Surg 2008, 90 Suppl 1:111-119

46. Slater BJ, Kwan MD, Gupta DM, Panetta NJ, Longaker MT: Mesenchymal cells for skeletal tissue engineering. Expert Opin Biol Ther 2008, 8:885-893.

47. Quintero AJ, Wright VJ, Fu FH, Huard J: Stem cells for the treatment of skeletal muscle injury. Clin Sports Med 2009, 28:1-11.

48. Tapp H, Hanley EN, Patt JC, Gruber HE: Adipose-derived stem cells: characterization and current application in orthopaedic tissue repair. Exp Biol Med 2009, 234:1-9.

49. Jackson WM, Nesti LJ, Tuan RS: Potential therapeutic applications of muscle-derived mesenchymal stem and progenitor cells. Expert Opin Biol Ther 2010, 10:505-517.

50. Chen FH, Rousche KT, Tuan RS: Technology Insight: adult stem cells in cartilage regeneration and tissue engineering. Nat Clin Pract Rheumatol 2006, 2:373-382

51. Bueno EM, Glowacki J: Cell-free and cell-based approaches for bone regeneration. Nat Rev Rheumatol 2009, 5:685-697.

52. Irwin RJ, Lerner MR, Bealer JF, Brackett DJ, Tuggle DW: Cardiopulmonary physiology of primary blast injury. J Trauma 1997, 43:650-655.

53. Sasser SM, Sattin RW, Hunt RC, Krohmer J: Blast lung injury. Prehosp Emerg Care 2006, 10:165-172.

54. Wolf SJ, Bebarta VS, Bonnett CJ, Pons PT, Cantrill SV: Blast injuries. Lancet 2009, 374:405-415.

55. Alison MR, Lebrenne AC, Islam S: Stem cells and lung cancer: future therapeutic targets? Expert Opin Biol Ther 2009, 9:1127-1141.

56. Stripp BR, Reynolds SD: Bioengineered lung epithelium: implications for basic and applied studies in lung tissue regeneration. Am J Respir Cell Mol Biol 2005, 32:85-86

57. de Andrade JA, Thannickal VJ: Innovative approaches to the therapy of fibrosis. Curr Opin Rheumatol 2009, 21:649-655.

58. Lee JW, Gupta N, Serikov V, Matthay MA: Potential application of mesenchymal stem cells in acute lung injury. Expert Opin Biol Ther 2009, 9:1259-1270

59. Chen H, Matsumoto K, Stripp BR: Bronchiolar progenitor cells. Proc Am Thorac Soc 2009, 6:602-606

60. Wolf YG, Rivkind A: Vascular trauma in high-velocity gunshot wounds and shrapnel-blast injuries in Israel. Surg Clin North Am 2002, 82:237-244.

61. Adams B, Xiao Q, Xu Q: Stem cell therapy for vascular disease. Trends Cardiovasc Med 2007, 17:246-251

62. Nesselmann C, Ma N, Bieback K, Wagner W, Ho A, Konttinen YT, Zhang H, Hinescu ME, Steinhoff G: Mesenchymal stem cells and cardiac repair. J Cell Mol Med 2008, 12:1795-1810.

63. Hong SJ, Traktuev DO, March KL: Therapeutic potential of adipose-derived stem cells in vascular growth and tissue repair. Curr Opin Organ Transplant 2010, 15:86-91.

64. Ferreira LS, Gerecht S, Shieh HF, Watson N, Rupnick MA, Dallabrida SM, VunjakNovakovic G, Langer R: Vascular progenitor cells isolated from human embryonic stem cells give rise to endothelial and smooth muscle like cells and form vascular networks in vivo. Circ Res 2007, 101:286-294.

65. Sun $\mathrm{G}$, Gerecht $\mathrm{S}$ : Vascular regeneration: engineering the stem cell microenvironment. Regen Med 2009, 4:435-447.

66. Joggerst SJ, Hatzopoulos AK: Stem cell therapy for cardiac repair: benefits and barriers. Expert Rev Mol Med 2009, 11:e20

67. Gersh BJ, Simari RD, Behfar A, Terzic CM, Terzic A: Cardiac cell repair therapy: a clinical perspective. Mayo Clin Proc 2009, 84:876-892.

68. Shi C, Zhu Y, Su Y, Cheng T: Stem cells and their applications in skin-cell therapy. Trends Biotechnol 2006, 24:48-52.

69. Charruyer A, Ghadially R: Stem cells and tissue-engineered skin. Skin Pharmacol Physiol 2009, 22:55-62.

70. $\mathrm{Li} \mathrm{LH}$, Clevers $\mathrm{H}$ : Coexistence of quiescent and active adult stem cells in mammals. Science 2010, 327:542-545. 
71. Shevchenko RV, James SL, James SE: A review of tissue-engineered skin bioconstructs available for skin reconstruction. J R Soc Interface 2010, 7:229-258.

72. Rhett JM, Ghatnekar GS, Palatinus JA, O'Quinn M, Yost MJ, Gourdie RG: Novel therapies for scar reduction and regenerative healing of skin wounds. Trends Biotechnol 2008, 26:173-180.

73. Ji Y, Christopherson GT, Kluk M, Amrani O, Jackson WM, Nesti L: Heterotopic Ossification Following Musculoskeletal Trauma: Modeling Stem and Progenitor Cells in Their Microenvironment. In Human Cell Transformation: Role of Stem Cells and the Microenvironment, Advances in Experimental Medicine and Biology. Volume 720. 1st Edition. Edited by Rhim JS, Kremer R. New York: Springer; 2011:39-50

74. Buchanan EP, Longaker MT, Lorenz HP: Fetal skin wound healing. Adv Clin Chem 2009, 48:137-161.

75. Hantash BM, Zhao L, Knowles JA, Lorenz HP: Adult and fetal wound healing. Front Biosci 2008, 13:51-61.

76. Chung KK, Perkins RM, Oliver JD 3rd: Renal replacement therapy in support of combat operations. Crit Care Med 2008, 36:S365-369.

77. Zubko R, Frishman W: Stem cell therapy for the kidney? Am J Ther 2009, 16:247-256.

78. Caplan Al: Why are MSCs therapeutic? New data: new insight. J Pathol 2009, 217:318-324.

79. Baraniak PR, McDevitt TC: Stem cell paracrine actions and tissue regeneration. Regen Med 2010, 5:121-143.

80. DARPA Blood Pharming Strategic Thrust [http://www.darpa.mil/Our_Work/ DSO/Programs/Blood_Pharming.aspx]

81. Timmins NE, Nielsen LK: Blood cell manufacture: current methods and future challenges. Trends Biotechnol 2009, 27:415-422.

82. Lee JW, Fang X, Gupta N, Serikov V, Matthay MA: Allogeneic human mesenchymal stem cells for treatment of E. coli endotoxin-induced acute lung injury in the ex vivo perfused human lung. Proc Natl Acad Sci U S A 2009, 106:16357-16362.

83. Pelte $\mathrm{CH}$, Chawla LS: Novel therapeutic targets for prevention and therapy of sepsis associated acute kidney injury. Curr Drug Targets 2009, 10:1205-1211.

84. Bielorai B, Toren A, Wolach B, Mandel M, Golan H, Neumann Y, Kaplinisky C, Weintraub M, Keller N, Amariglio N, Paswell J, Rechavi G: Successful treatment of invasive aspergillosis in chronic granulomatous disease by granulocyte transfusions followed by peripheral blood stem cell transplantation. Bone Marrow Transplant 2000, 26:1025-1028.

85. Ross JJ: Angiogenic gene therapy as a potential therapeutic agent in chronic osteomyelitis. Med Hypotheses 2006, 67:161-163.

86. Hou T, Xu J, Li Q, Feng J, Zen L: In vitro evaluation of a fibrin gel antibiotic delivery system containing mesenchymal stem cells and vancomycin alginate beads for treating bone infections and facilitating bone formation. Tissue Eng Part A 2008, 14:1173-1182.

87. Kode JA, Mukherjee S, Joglekar MV, Hardikar AA: Mesenchymal stem cells: immunobiology and role in immunomodulation and tissue regeneration. Cytotherapy 2009, 11:377-391.

88. Seggewiss R, Einsele $\mathrm{H}$ : Immune reconstitution after allogeneic transplantation and expanding options for immunomodulation: an update. Blood 2010, 115:3861-3868.

89. Shi Y, Hu G, Su J, Li W, Chen Q, Shou P, Xu C, Chen X, Huang Y, Zhu Z, Huang X, Han X, Xie N, Ren G: Mesenchymal stem cells: a new strategy for immunosuppression and tissue repair. Cell Res 2010, 20:510-518.

90. García-Castro J, Trigueros C, Madrenas J, Pérez-Simón JA, Rodriguez R, Menendez P: Mesenchymal stem cells and their use as cell replacement therapy and disease modelling tool. J Cell Mol Med 2008, 12:2552-2565

91. Scherer MR, Schubert MC: Traumatic brain injury and vestibular pathology as a comorbidity after blast exposure. Phys Ther 2009, 89:980-992.

92. Krysinska K, Lester D, Martin G: Suicidal behavior after a traumatic event JTrauma Nurs 2009, 16:103-110.

93. Ling G, Bandak F, Armonda R, Grant G, Ecklund J: Explosive blast neurotrauma. J Neurotrauma 2009, 26:815-825.

94. Tamaki K, Yamada K, Nakamichi N, Taniura H, Yoneda Y: Transient suppression of progenitor cell proliferation through NMDA receptors in hippocampal dentate gyrus of mice with traumatic stress experience. J Neurochem 2008, 105:1642-1655.

95. Lucassen PJ, Meerlo P, Naylor AS, van Dam AM, Dayer AG, Fuchs E, Oomen CA, Czéh B: Regulation of adult neurogenesis by stress, sleep disruption, exercise and inflammation: Implications for depression and antidepressant action. Eur Neuropsychopharmacol 2010, 20:1-17.

96. Eisch AJ, Cameron HA, Encinas JM, Meltzer LA, Ming G-L, Overstreet-Wadiche LS: Adult neurogenesis, mental health, and mental illness: hope or hype? J Neurosci 2008, 28:11785-11791

97. Little MP: A multi-compartment cell repopulation model allowing for inter-compartmental migration following radiation exposure, applied to leukaemia. J Theor Biol 2007, 245:83-97.

98. Kadar T, Dachir S, Cohen L, Sahar R, Fishbine E, Cohen M, Turetz J, Gutman H Buch H, Brandeis R, Horwitz V, Solomon A, Amir A: Ocular injuries following sulfur mustard exposure--pathological mechanism and potential therapy. Toxicology 2009, 263:59-69.

99. Hayden PJ, Petrali JP, Stolper G, Hamilton TA, Jackson GR, Wertz PW, Ito S, Smith WJ, Klausner M: Microvesicating effects of sulfur mustard on an in vitro human skin model. Toxicol In Vitro 2009, 23:1396-1405.

100. Collombet J-M, Mourcin F, Grenier N, Four E, Masqueliez C, Baubichon D, Lallement G, Hérodin F: Effect of soman poisoning on populations of bone marrow and peripheral blood cells in mice. Neurotoxicology 2005, 26:89-98.

101. Rider TH, Petrovick MS, Nargi FE, Harper JD, Schwoebel ED, Mathews RH, Blanchard DJ, Bortolin LT, Young AM, Chen J, Hollis MA: A B cell-based sensor for rapid identification of pathogens. Science 2003, 301:213-215.

102. Pancrazio JJ, Whelan JP, Borkholder DA, Ma W, Stenger DA: Development and application of cell-based biosensors. Ann Biomed Eng 1999, 27:697-711.

103. Nirmalanandhan VS, Sittampalam GS: Stem cells in drug discovery, tissue engineering, and regenerative medicine: emerging opportunities and challenges. J Biomol Screen 2009, 14:755-768.

104. Bardelli S: Stem cell biobanks. J Cardiovasc Trans/ Res 2010, 3:128-134.

105. ISCBI: Consensus guidance for banking and supply of human embryonic stem cell lines for research purposes. Stem Cell Rev 2009, 5:301-314.

106. Jackson WM, Aragon AB, Djouad F, Song Y, Koehler SM, Nesti L, Tuan RS: Mesenchymal progenitor cells derived from traumatized human muscle. J Tissue Eng Regen Med 2009, 3:129-138.

107. D'Alleyrand JC, Dutton RP, Pollak AN: Extrapolation of battlefield resuscitative care to the civilian setting. J Surg Orthop Adv 2010, 19:62-69.

108. Lanska DJ: Historical perspective: neurological advances from studies of war injuries and illnesses. Ann Neurol 2009, 66:444-459.

109. NIH Stem Cell Information [http://stemcells.nih.gov/info/]

doi:10.1186/scrt81

Cite this article as: Christopherson GT, Nesti L: Stem cell applications in

military medicine. Stem Cell Research \& Therapy 2011, 2:40 